\title{
Prediction of Olympic Medals Based on Gray Theory \\ Qingxiang Hu
}

School of Energy Power and Mechanical Engineering, North China Electric Power University, Baoding 071000, China.

13483767024@163.com

Keywords: gray theory, Olympic medal, predict

\begin{abstract}
In today's data age, it is a trend that countries rely on data analysis to support resources allocation of the Olympic Games to obtain the maximum input-output ratio. This paper analyzes the number of medals won by China in the last 8 Olympic Games, and uses the gray theory to predict the total number of medals that China will receive in the 2020 Tokyo Olympic Games.
\end{abstract}

\section{Introduction}

The Olympic Games is the top event of competitive sports, the number of medals and the national ranking is not only a exemplification of national sports competition level, but also a exemplification of the national economy, political and comprehensive strength. By forecasting the Olympic medals, country can receive the maximum medal return at a certain capital investment. In this paper, the gray forecasting model GM (1.1) is used to obtain the number of medals won by China in the 32nd Olympic Games in 2020[1].

\section{The step of Gray Theory Forecasting Model}

The steps of Gray Theory Forecasting Model $(\mathrm{GM}(1,1))$ are as follows:

Firstly, we suppose the original data sequence $X^{(0)}$ :

$$
X^{(0)}=\left(x^{(0)}(1), x^{(0)}(2), \cdots, x^{(0)}(n)\right)
$$

Then set the generated sequence $X^{(1)}$ :

$$
X^{(1)}=\left(x^{(1)}(1), x^{(1)}(2), \cdots, x^{(1)}(n)\right)
$$

Where $x^{(1)}(k)=\sum_{i=1}^{k} x^{(0)}(i), k=1,2, \cdots, n$

And then record $Z(t)$ as Immediate Mean Generation Sequence of $X^{(1)}$ :

$$
Z(t)=\left(Z^{(1)}(1), Z^{(1)}(2), \cdots Z^{(1)}(n)\right)
$$

Where $z^{(1)}(k)=0.5 x^{(1)}(k)+0.5 x^{(1)}(k-1), k=2, \cdots, n$

Establish the differential equation (gray model):

$$
\frac{d X}{d t}^{(1)}+a X^{(1)}=b
$$

And the whitening equation:

$$
X^{(0)}(k)+a Z^{(1)}(k)=b
$$

Set $B=(a, b)^{(T)}$ as a parameter sequence and we can get:

$$
Y_{N}=\left(\begin{array}{c}
X^{(0)}(2) \\
X^{(0)}(3) \\
\vdots \\
X^{(0)}(n)
\end{array}\right), B=\left(\begin{array}{cc}
-Z^{(1)}(2) & 1 \\
-Z^{(1)}(3) & 1 \\
\vdots & \vdots \\
-Z^{(1)}(n) & 1
\end{array}\right)
$$


Replace the differential equation with difference equation; the differential equation can be transformed into:

Abbreviated as:

$$
\left(\begin{array}{c}
x^{(0)}(2) \\
x^{(0)}(3) \\
\vdots \\
x^{(0)}(n)
\end{array}\right)=\left(\begin{array}{cc}
-\frac{1}{2}\left[\mathrm{x}^{(1)}(2)+\mathrm{x}^{(1)}(1)\right] & 1 \\
-\frac{1}{2}\left[\mathrm{x}^{(1)}(3)+\mathrm{x}^{(1)}(2)\right] & 1 \\
\vdots & \vdots \\
-\frac{1}{2}\left[\mathrm{x}^{(1)}(n)+\mathrm{x}^{(1)}(n-1)\right] & 1
\end{array}\right)
$$

$$
Y_{N}=X B
$$

With the least square method, we get the solution:

$$
B=(a b)^{T}=\left(X^{T} X\right)^{-1} X^{T} Y_{N}
$$

Plugging into the original differential equation, we obtain:

$$
X^{(1)}(k+1)=\left[X^{(0)}(1)-b / a\right] e^{-a k}+b / a
$$

According to this, we solve the sequence $X^{(1)}$ and then by accumulating, we obtain:

$$
X^{(0)}(k)=X^{(1)}(k)-X^{(1)}(k-1)
$$

Where the sequence $X^{(0)}$ is the simulated value of the original sequence and when $\mathrm{k} \geqslant \mathrm{n}$, it will be the predicted values for the original series, which is result we want.

\section{Data processing and forecasting}

The total number of medals of China since the 1988 Seoul Olympic Games is shown in Table 1.

Table 1: The number of Olympic Game medals of China

\begin{tabular}{ccccccccc}
\hline Years & 1988 & 1992 & 1996 & 2000 & 2004 & 2008 & 2012 & 2016 \\
\hline $\begin{array}{c}\text { Medal } \\
\text { number }\end{array}$ & 28 & 54 & 50 & 59 & 63 & 100 & 88 & 70 \\
\hline
\end{tabular}

Facts have proved that the Olympic project has a very significant host country effect, and the relevant literature quantitatively calculated the host effect value is 0.1131[2]. Before the solution, considering the host country effect [3], China, as the host of the 2008 Beijing Olympic Games, its medals number will be at least $11.31 \%$ higher than its theoretical value. Therefore, the theoretical value of the number of medals that China should receive in the 2008 Olympic Games should be: $100 \times(1-0.1131)=88.69 .100 \times(1-0.1131)=88.69$. After deducting the host country effect, the theoretical value of the medals of the previous Olympic Games are shown in Table 2:

Table 2: The theoretical number of Olympic Game medals of China

\begin{tabular}{ccccccccc}
\hline Years & 1988 & 1992 & 1996 & 2000 & 2004 & 2008 & 2012 & 2016 \\
\hline $\begin{array}{c}\text { Medal } \\
\text { number }\end{array}$ & 28 & 54 & 50 & 59 & 63 & 88.69 & 88 & 70 \\
\hline
\end{tabular}

Through Matlab programming, we get the predictive sequence as: 
$X^{(0)}=\left(x^{(0)}(1), x^{(0)}(2), \cdots, x^{(0)}(9)\right)=(28.0000,52.9694,57.2282,61.8295,66.8008,72.1718$ ,77.9746,84.2439,91.0174)

difference ratio $\mathrm{C}$ and the small error probability $\mathrm{P}$ can be used to test the prediction accuracy and the standard is as follows:

1) When $\mathrm{C}<0.35$ and $\mathrm{P}>0.95$, the prediction accuracy is excellent;

2) When $\mathrm{C}<0.45$ and $\mathrm{P}>0.80$, the prediction accuracy is good;

3) When $\mathrm{C}<0.50$ and $\mathrm{P}>0.70$, the prediction accuracy is acceptable;

4) When $\mathrm{C}<0.65$ and $\mathrm{P}<0.70$, the prediction accuracy is unqualified.

Accuracy test results shows: $\mathrm{C}=0.480523, \mathrm{P}=0.75$ and the prediction accuracy is acceptable.

In order to improve the prediction accuracy, we transformed the original sequence [4] and take the logarithm of 10 to get Table 3:

Table 3: The transformed number of Olympic Game medals of China

\begin{tabular}{ccccccccc}
\hline Years & 1988 & 1992 & 1996 & 2000 & 2004 & 2008 & 2012 & 2016 \\
\hline $\begin{array}{c}\text { Medal } \\
\text { number }\end{array}$ & 1.4472 & 1.7324 & 1.6990 & 1.7709 & 1.7993 & 1.9479 & 1.9445 & 1.8451 \\
\hline
\end{tabular}

Through Matlab programming, we get the predictive sequence as:

$$
\begin{aligned}
& X^{(0)}{ }^{\prime}=\left(x^{(0)}(1)^{\prime}, x^{(0)}(2)^{\prime}, \cdots, x^{(0)}(9) '\right)=(1.4472,1.7148,1.7487,1.7832,1.8184,1.8544 \\
& , 1.8910,1.9283,1.9664)
\end{aligned}
$$

Accuracy test results shows: $\mathrm{C}=0.34912, \mathrm{P}=1$, the prediction accuracy is excellent.

After ensuring the model accuracy, we restore the converted data to get the total number of medals of China in the Tokyo Olympic Games as: $10^{1.9664}=92 / 93$.

\section{Conclusions}

Based on China's previous number of Olympic Game medals, this paper uses the gray theory to obtain the number of medals won by China at the 2020 Tokyo Olympic Games is 92/93, which has a high prediction accuracy.

\section{References}

[1]. Deng Ju-long, Grey Theory [M], Huazhong University of Science and Technology Press,2005:42

[2]. Yan Yu-yang, Prediction on Olympic Medals Based on Grey Theory [J], Sichuan University of Arts and Science Journal, 2011,(05):21-23.

[3]. Deng Yun-long, Analysis on Olympics Host Country Effects and of the Competition Preparation for Chinese Delegation [J], China Sport Science And T echnology,2007,(01):3-6

[4]. Cui Li-zhi, Grey Forecast Technology and Its Application Research [D], Nanjing University of 
Aeronautics and Astronautics, Mar, 2010. 